\title{
IMPROVING CUTTING CAPABILITY OF PLASMA BEAM BY MODIFYING THE NOZZLE GEOMETRY SUPLIED BY FEM
}

\author{
Málek M.*, Mičian M.**
}

\begin{abstract}
The paper deals with the effect of nozzle orifice geometry to the shape of plasma beam. Investigation focused to improvement cutting features like cutting speed, width and quality of cutting gap. The FEM analyse in the program Ansys - Fluent has been used for predictions behaviour of plasma beam depends on the modified nozzle orifice, especially influencing the plasma flow rate. The simulation results were the basis to produce a specific modified nozzle shape. Experimental cuts were made on S235 steel of $10 \mathrm{~mm}$ thickness. Based on all the analyses performed, the simulation showed that the shape of the orifice in the plasma torch nozzle affects the shape of the plasma beam. However, the positive results were not confirmed in the evaluation of the cut quality.
\end{abstract}

Keywords: Plasma cutting, Plasma beam, Nozzle geometry, Flow ratio, Cutting capability.

\section{Introduction}

Thermal plasma processes have proven their technological advantage in a wide variety of fields for over 40 years. The plasma arc torches are, generally, the primary component of these processes that include plasma spraying, ultrafine particle synthesis, metal welding and cutting but also, extractive metallurgy, waste treatment, and biogas production. These torches operate as thermal, chemical, and electrical devices. The features that make thermal plasmas attractive are a high energy density $\left(1.10^{6}-1.10^{7} \mathrm{~J}^{-\mathrm{m}^{-3}}\right)$ that comes with high heat flux density $\left(1.10^{7}-1.10^{9} \mathrm{~W} \cdot \mathrm{m}^{-2}\right)$ and high processing rates (Trelles, 2009). The main criteria of efficiency in the design of plasma torches for air-plasma cutting of metals are productivity, cutting quality and reliability of plasma equipment. The efficiency of this system determines the high degree of heat input and kinetic properties of the plasma arc (jet), the durability of the cathode and nozzle of the plasma torch (Anakhov, 2019). In production, only the stable kind of plasma is used, which means, the plasma arc is focused as tightest diameter as possible. These features lead to higher heat and dynamic impact to the surface (Hypertherm, 2019). For this purpose, is necessary control and regulate features like temperature, power and outlet speed. Plasma gas, kind of nozzle, parameters of electric power source and degree of plasma ionization are the main factors, which affect the features mentioned above. For purpose to cutting various metals are used different kind of nozzle, with specific geometry of functional nozzle part and with their various constructions (Benko, 1988; Dunovský, 1984; Kašpar, 1990). This article deals with modifying functional part of nozzle geometry, with FEM support, to achieve positive influence to the shape of plasma beam and cut edge properties, including dross formation, surface roughness and edge shape.

\section{Design of plasma torch nozzle modification}

The dimensions of conventional plasma nozzle and electrode have been measured, to create visual 3D models. Also the dimensional correlation between electrode and nozzle was found out. These models were used to create environment for simulation. All dimensions were measured by certificated and calibrated measuring instruments. Fig. 1 shows 3D geometric model of plasma torch.

\footnotetext{
Ing. Miloslav Málek: University of Žilina, Faculty of Mechanical Engineering, Univerzitná 1, 01026 Žilina, SK, miloslav.malek@fstroj.uniza.sk

** Assoc. Prof. Miloš Mičian, PhD.: University of Žilina, Faculty of Mechanical Engineering, Univerzitná 1, 01026 Žilina, SK, milos.mician@fstroj.uniza.sk
} 


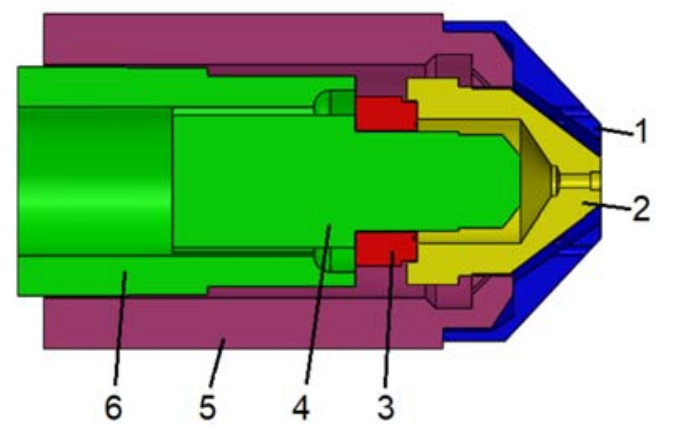

1 - shield

2 - reference nozzle

3 - swirl ring

4 - electrode

5 - retaining cap,

6 - torch body

Fig. 1: 3D geometric model of plasma torch.

For this research were investigated 9 modification of plasma nozzle. The modifications consisted of changing the shape of the nozzle orifice in order to affect the plasma outflow. All adjustments have been made in relation to the following requirements: conventional technology for the manufacturing, short production time and low cost production. Fig. 2 shows example of conventional nozzle and nozzle orifice with modification, in which obtained the best simulation results. Convergent - divergent shape of nozzle orifice was reached by drill bit for a centre holes ISO $6411-\mathrm{R} 1,25 / 3,15$. The orifice was drilled from the outside of the nozzle.
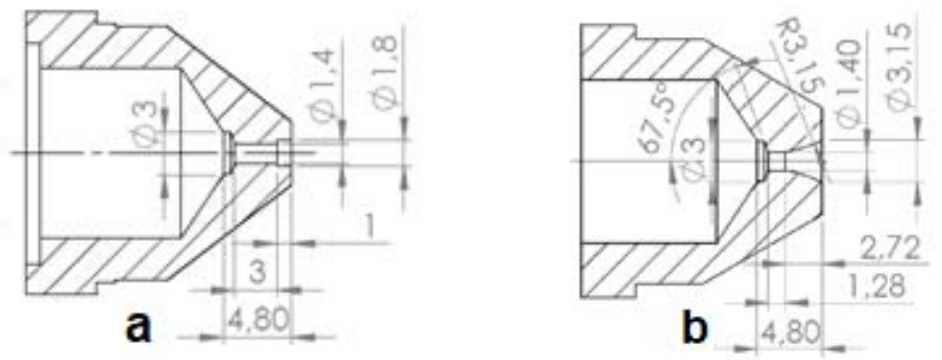

Fig. 2: Geometric dimensions of the nozzle; a) conventional shape, b) modified shape.

\section{Plasma flow FEM analyse}

The FEM analyse in the program Ansys - Fluent was used for predictions behaviour of plasma beam depends on the modified nozzle orifice. To specify the boundary conditions for pressure, velocity and other variables was used a typical computational domain as shown in Fig. 3a. It has boundary conditions of the types inlet, wall, axis of symmetry and outlet. Inlet pressure was set for $2.26 \mathrm{MPa}$ with temperature around $1200 \mathrm{~K}$. Outlet pressure was set for $39.4 \mathrm{kPa}$ with temperature $273.2 \mathrm{~K}$. In the simulation, the plasma was replaced with an ideal gas. With this setup, was obtained the best match of shape between plasma beam during the starting arc and simulation, at conventional nozzles. The program automatically generated the finite element mesh was very coarse and inaccurate. After suitable compacting mesh to achieve better results (Fig. 3b).

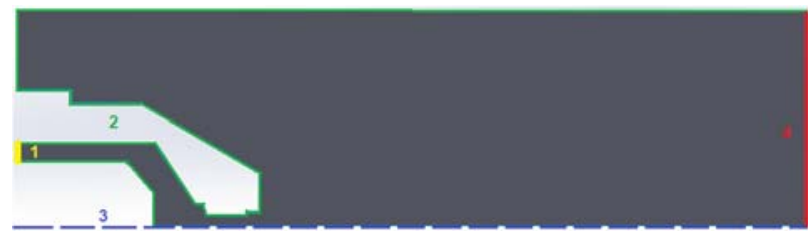

a)

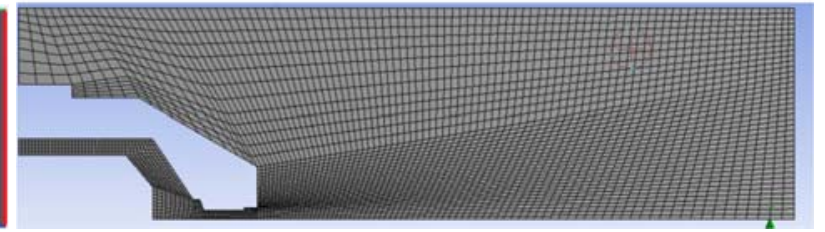

b)

Fig. 3: 2D simulation model with: a) specify the boundary conditions, 1-inlet, 2-wal, 3-axis of symmetry, 4-outlet; b) finite element mesh.

The simulations were focused to obtain shape of plasma beam during flow out of nozzle. The velocity range is represented with colour scale, as it is shown in Fig. 4. The simulations were focused on speed investigation, because of the dynamic effect in the cutting process. 


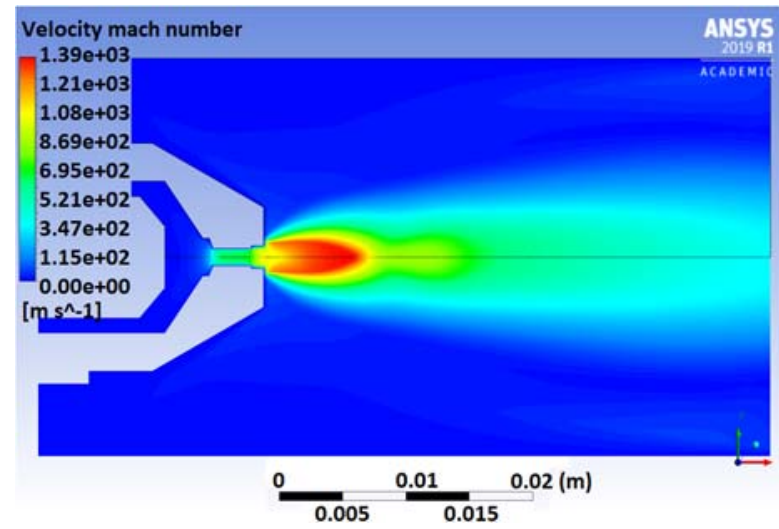

a)

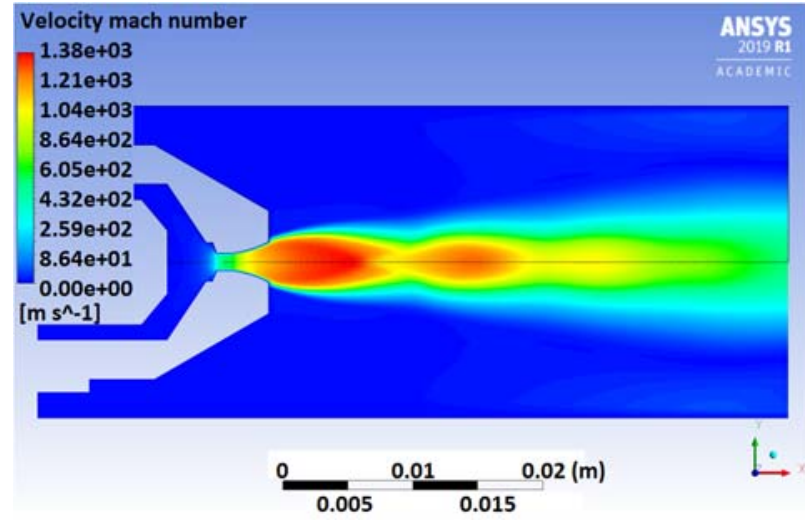

b)

Fig. 4: Results of flow rate simulation: a) conventional nozzle; b) modified nozzle.

The primary phase of plasma of conventional nozzle with high flow velocity, which is represented with red area, corresponds with shape of pilot arc (Fig. 4a). The primary phase of modified nozzle has longer range (Fig. 4b). The velocity shape has a little bit divergent behaviour, but there was also second phase with high flow velocity, represented with bright yellow area, which could have positive affect to dynamic pressure. The green area, with mediate flow velocity, has cylindrical shape at both cases, but the modified nozzle had longer range at this area, which indicated better cutting features for thicker workpieces.

\section{Experimental cuts}

The experiment cuts were conducted using air-plasma arc cutting system with Cebora 3600, DC power supply with maximum current $90 \mathrm{~A}$ and a remote high frequency starter. The plasma torch was controlled via CNC system. The cutting parameters were: direct current $70 \mathrm{~A}$, cutting speed $610 \mathrm{~mm} . \mathrm{min}^{-1}$ and pressure of air $0.3 \mathrm{MPa}$. S235 steel sheet with a thickness of $10 \mathrm{~mm}$ was used to compare the cutting properties of conventional and modified nozzle. The plasma torch was $1.5 \mathrm{~mm}$ above the steel plate. The photos of pilot plasma arc have been made with digital camera, and with additional light about power of $1000 \mathrm{~W}$. To protection of camera lens was used welding glass with degree of darkness DIN 5. In Fig. 5a is shown pilot plasma arc for conventional and modified nozzle and in Fig. 5b is shown cutting plasma beam for conventional and modified nozzle, where a decrease in plasma beam ionization can be observed in the modified nozzle. The visual evaluation did not confirm the result of the simulation where the speed range was greater in the primary and secondary phases. However, the plasma beam shape in modified nozzle, had a more pointed shape than a conventional nozzle, which could obtain better cutting features to cut thin sheet. Cutting edge (0) made by modified nozzle had wider cutting gap and also the perpendicular deviation is bigger.
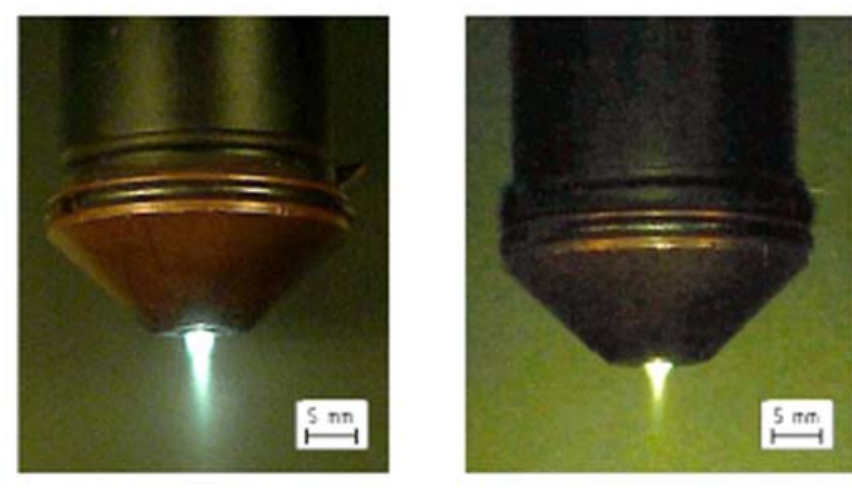

a)

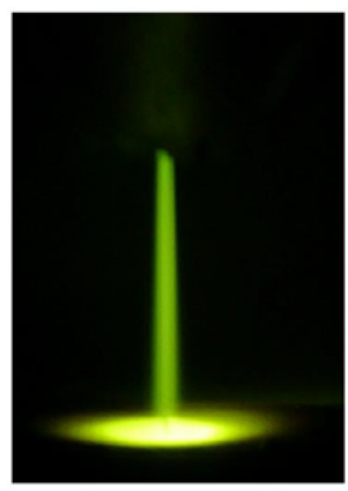

b)

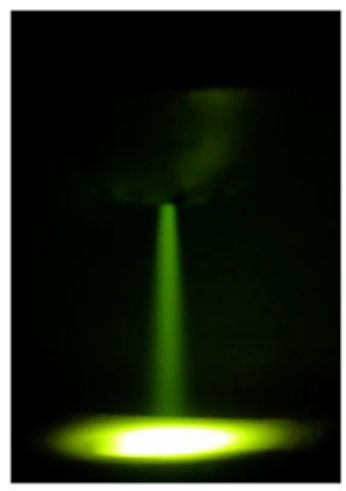

Fig. 5: Photographic images of: a) pilot plasma beam for conventional (left side) and modified nozzle (right side); b) cutting plasma beam for conventional (left side) and modified nozzle (right side). 

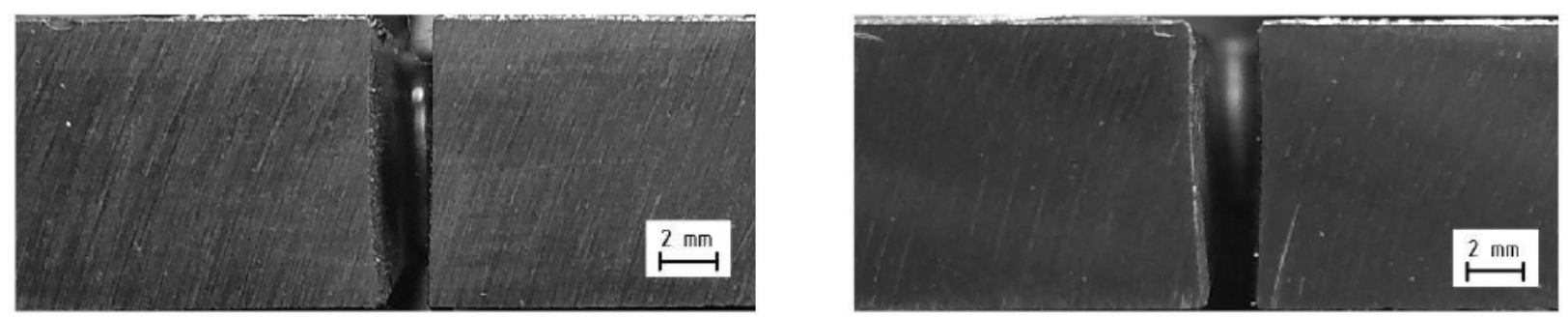

Fig. 6: Macrostructure of cutting gap with conventional (left side) and modified nozzle (right side).

\section{Conclusions}

This paper deals with effect of modifying nozzle orifice onto the shape of plasma beam and cutting capability. The priority of research was to improved cutting features like cutting speed, surface roughness of cutting edge, possibilities to cut thicker sheet plate etc. Modified nozzle orifices were inspired by shape of convergent-divergent nozzle, or de Laval nozzle, which is used widely for supersonic flow speed. However, the modification should be easily manufactured with conventional technology, therefore the modified nozzle was designed with shape of drill bit for centre holes DIN 6411 type R. The simulations were made for predictions flow ratio behaviour. Simulation of conventional nozzle had similar shape as pilot plasma arc. The shape of pilot plasma arc for modified nozzle, did not correspond to the result of simulation, and other positive results of simulation, did not reached during experimental cutting. The simulations did not correspond to the experimental results, because:

- the simulations were simplified to the $2 \mathrm{D}$ model,

- there were not consider aspect of swirl ring.

For another research, it should be making 3D simulations with considering effect of swirl ring, shielding gas and another part of plasma torch, like shield. However, experimental cuts could be made using modified nozzle for a steel plate with thickness $\leq 2 \mathrm{~mm}$.

\section{Acknowledgement}

This research was funded by KEGA, grant number KEGA 009ŽU-4/2019. All the financial support is gratefully acknowledged.

\section{References}

Anakhov, S. V., Matushkin, A. V. and Pyckin, Y. A. (2019) Effect of a gas-vortex stabilization method on the kinematic properties of the jet in metal-cutting plasmatrons. Materials Science and Engineering, pp. 1-9, IOP Conference Series.

Benko, D. M. (1988) Plasma spraying of metal and ceramic powders. Bratislava: Alfa, (in Slovak).

Dunovský, J., Kuncipál, V. and Pilous, J. (1984). New technologies in welding, Praha: SNTL (in Czech).

Hypertherm (2019) Hypertherm. Retrieved from Define plasma - Plasma cutting processes: www.hypertherm.com.

Kašpar, O. J. (1990) Thermal spraying and their industrial use. Praha: SNTL (in Czech).

Kim, S., Heberlein, J., Lindsay, J. and Peters, J. (2012) Torch design modification using Micro-jets to suppress fluid dynamic instabilities in plasma arc cutting. Plasma Chem Plasma Process, 45-63.

Mahajan, M. S. (2010) Numerical modeling of plasma cutting torches.

Trelles, J. P., Chazelas, C., Vardelle, A. and Herbelein, J. V. R. (2009) Arc plasma torch modeling. Journal of Thermal Spray Technology, 728-752. 